\title{
Regional myocardial velocity imaged by magnetic resonance in patients with ischaemic heart disease
}

Stefan P Karwatowski, Raad H Mohiaddin, Guang Z Yang, David N Firmin, Martin St John Sutton, S Richard Underwood

\begin{abstract}
Objective-To assess the pattern of global and regional left ventricular long axis motion during early diastole in patients with ischaemic heart disease with and without myocardial infarction using magnetic resonance velocity mapping.
\end{abstract} Design-Prospective study of 26 patients with a history of myocardial infarction (age 29-78, mean 55 years) and 21 patients with coronary artery disease without infarction (age range 39-71, mean 58 years). Values were compared with a control group (19 controls, age 35-76, mean 52 years) with a low likelihood of cardiovascular disease.

Results-Regional long axis velocity varied with time and position around the ventricle. All measurements were taken at the time of maximum early diastolic long axis velocity. Patients with coronary artery disease without infarction had lower values for maximum (mean (SD)) (99 (30) $v 125(33) \mathrm{mm} / \mathrm{s}, P<0.05$ ) and mean peak early diastolic wall motion (63 (13) $v 82(22) \mathrm{mm} / \mathrm{s}, P<0.05)$ than controls. The coefficient of variation showed greater inhomogeneity of relaxation in patients than in controls $(38(18) \% v 27$ (10)\%). All values were lower in patients with previous infarction than in patients with coronary artery disease without infarction and normal subjects. In patients with previous myocardial infarction the maximum (mean (SD)) early diastolic velocity was $80(22) \mathrm{mm} / \mathrm{s}(P<$ 0.01 compared with controls and $P<0.05$ compared with patients without infarction) and the mean (SD) velocity was 47 (18) $\mathrm{mm} / \mathrm{s}(P<0.01$ compared with controls). The coefficient of variation was greater (52 (33)\%) than for controls ( $P$ < $0 \cdot 05)$ and patients with coronary artery disease without infarction. 18 of 26 patients with previous myocardial infarction and 13 of 21 patients with coronary artery disease without infarction had regional abnormalities corresponding to areas of fixed or reversible ischaemia on exercise electrocardiography or thallium myocardial perfusion tomography.

Conclusions-Magnetic resonance velocity mapping can be used to assess regional long axis myocardial velocity. Ischaemic heart disease causes alterations in the patterns of left ventricular long axis velocity during early diastole.

(Br Heart f 1994;72:332-338)
Left ventricular diastolic function may be abnormal at rest in patients with ischaemic heart disease ${ }^{12}$ and the abnormalities may be more pronounced during acute ischaemia. ${ }^{34}$ During ischaemia, subendocardial blood flow is compromised earlier and to a greater extent than other layers and this territory is also subjected to the highest wall stress. ${ }^{56}$ Subendocardial myocytes are oriented along the long axis of the heart ${ }^{7}$ and contribute to the descent of the base of the heart towards the apex during systole, thus playing an important part in systolic ejection. During systole, elastic energy is stored in the myocardial wall. During diastole the release of this stored energy leads to an increase in ventricular volume and a decrease in intraventricular pressure which facilitates early ventricular filling.

Abnormal long axis function has been documented in the absence of impaired short axis function. ${ }^{8}$ Unlike radial contraction, long axis motion is difficult to assess, although it may provide an early indication of ventricular dysfunction. ${ }^{89} \mathrm{M}$ mode echocardiography has been used successfully; it has good temporal resolution, but measurements are taken from only three sites. Magnetic resonance imaging is a safe non-invasive technique which can produce tomographic images of the body in any plane with high spatial and temporal resolution. Magnetic resonance velocity mapping is a technique which encodes the velocity of moving structures quantitatively in the phase of the magnetic resonance signal and hence provides accurate measurements of velocity. The combination of anatomical magnetic resonance imaging and velocity mapping can be used to study the regional long axis velocity of the left ventricle, a measurement not available with any other technique. Using magnetic resonance velocity mapping we have studied the pattern of long axis myocardial velocity in controls. ${ }^{10}$ The aim of this study was to test the ability of magnetic resonance velocity mapping to assess abnormal diastolic long axis myocardial velocity in patients with ischaemic heart disease.

\section{Patients and methods}

STUDY POPULATION

Twenty six patients with a history of myocardial infarction (age 29-78, mean 55 years) and 21 patients with coronary artery disease but no previous infarction (age 39-71, mean 58 years) were studied. Values were compared with a group of control subjects of a similar age but with a low likelihood of ischaemic heart disease (19 controls, age 35-76, mean 


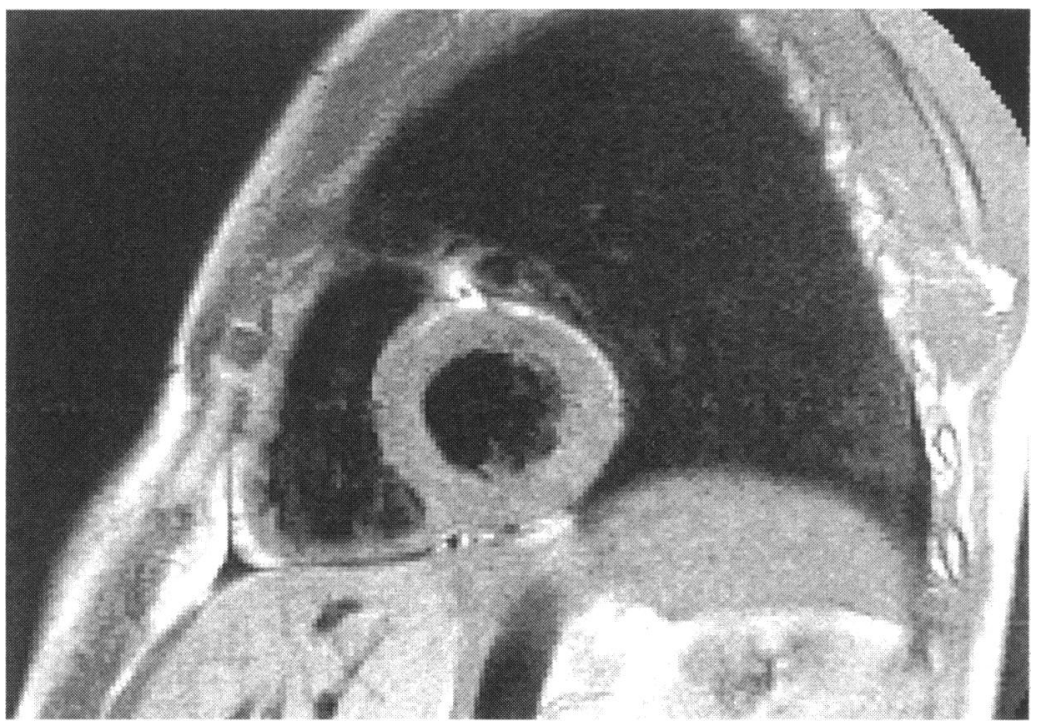

Figure 1 Magnetic resonance spin echo image of basal short axis plane of the left ventricle; velocity information was encoded through this plane.

52 years). The findings in the control subjects have previously been published..$^{10}$ Eleven normal subjects and eight patients underwent immediate repeat imaging to assess short term reproducibility. The patients were recruited from the outpatient department of the Royal Brompton National Heart and Lung Hospital. Previous myocardial infarction was diagnosed from conventional clinical, electrocardiographic, and enzyme parameters. Patients with coronary artery disease without infarction had reversible ischaemia documented by exercise electrocardiography or stress thallium perfusion tomography. Beta blockers were withheld 72 hours before the study, long acting calcium antagonists the day before, and other cardiac drugs, except short acting nitrates, were withheld on the day of the study. Patients requiring loop diuretics or who had had a previous bypass operation were excluded. The study was approved by the ethical committee of the Royal Brompton National Heart and Lung Hospital. All subjects gave informed consent.

\section{METHODS}

A modified Picker $0.5 \mathrm{~T}$ machine was used to acquire cardiac images with a surface receiver coil. Conventional spin echo sequences (echo time $40 \mathrm{~ms}$ ) were used to document anatomy and to define the vertical and horizontal long axis and a basal short axis plane at end systole (fig 1). Using a cine gradient echo sequence ${ }^{11}$ velocity maps were acquired in a basal short axis plane below the mitral annulus where the septum and lateral wall are muscular. Velocity was encoded through this plane-that is, parallel to long axis motion-the velocity window was set at $\pm 0 \cdot 15-0.25 \mathrm{~m} / \mathrm{s}$. All studies were performed using 192 phase encoding steps, each averaged from two repeat measurements. The field of view was between 35 and $40 \mathrm{~cm}$, giving a pixel size of $1.4 \times 1.8$ to $1.6 \times 2.1$ $\mathrm{mm}$ with $10 \mathrm{~mm}$ slice thickness. The first image was acquired $18 \mathrm{~ms}$ after the $R$ wave and the temporal resolution was $25 \mathrm{~ms}$, giving 24-31 images for each cardiac cycle. To assess short term reproducibility image acquisition was repeated in 11 normal subjects and eight patients without removing the subject from the magnet. Intraobserver variability was assessed by the analysis of 10 sets of data on two separate days.

\section{ANALYSIS}

Reference and velocity encoded phase images were subtracted to produce velocity maps of long axis myocardial motion (fig 2) and the zero point was corrected by the manual selection of stationary structures over the chest wall. The endocardial and epicardial boundaries were traced manually. The myocardium was divided into 16 segments and the mean velocity in each segment was calculated. Velocity curves were constructed for the entire cardiac cycle (fig 3).
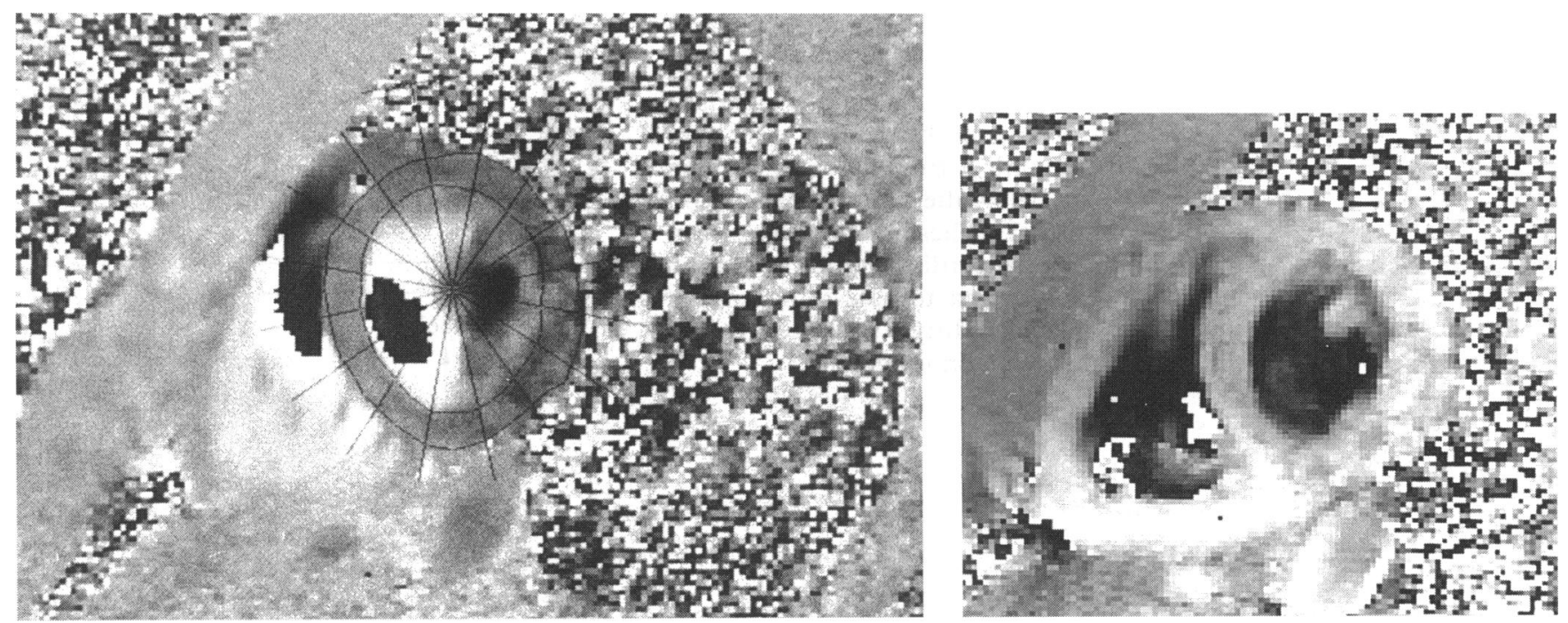

Figure 2 Velocity maps of left ventricular long axis motion. The image on the left is during systole, showing a myocardial ring with dark grey pixels indicating motion out of the plane towards the viewer. The image on the right is during early diastole; pixels are lighter shades of grey indicating motion into the plane, away from the viewer. The left hand image also shows the hand drawn boundaries used to define the myocardial ring which the image processing package has divided into 16 segments before calculating the velocity. 
Figure 3 Regional long axis wall velocity through the cardiac cycle in a normal subject. Initial displacement of the base of heart during

transformation from

ellipsoid to spheroid, point isovolumic contraction, $b$, before descent of the base during systole, c. Early diastole is accompanied by rapid motion of the base away from the apex, $d$.

This is followed by a brief period of motion back towards the base, e. All measurements were made at point $d$. a. Velocity drops during

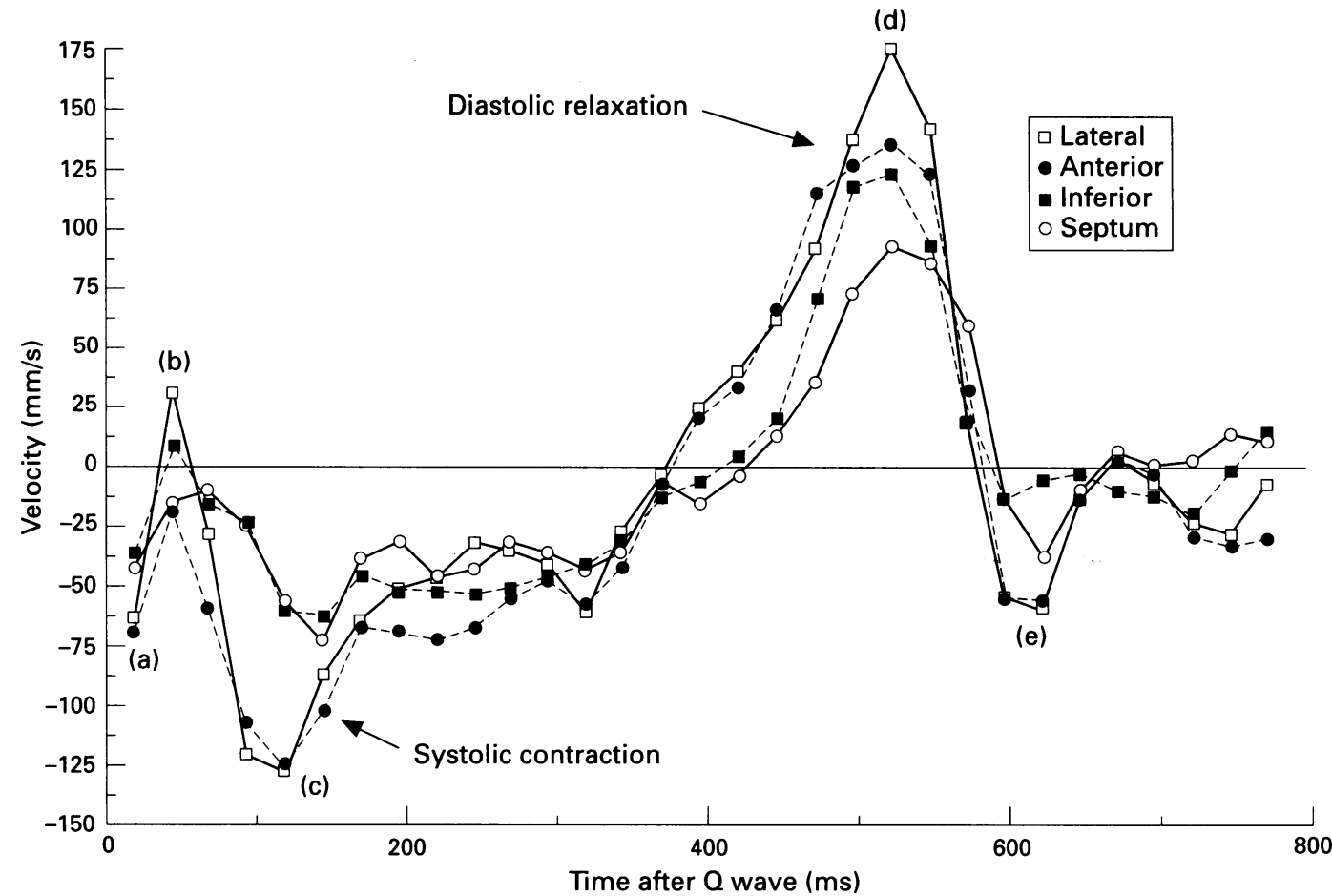

GLOBAL MEASURES OF EARLY DIASTOLIC WALI MOTION

All global measurements were made at the time of peak early diastolic myocardial velocity. Peak, mean, and minimum early diastolic velocity were measured. The variability of regional velocity at the time of peak early diastolic velocity was used as a marker of homogeneity of myocardial relaxation. It was expressed as the coefficient of variation.

Coefficient of variation $=$

$$
\frac{\text { Standard deviation of velocity }}{\text { Mean velocity }} \times 100 \%
$$

\section{CORRELATION WITH ANATOMICAL SITE OF} ISCHAEMIA

As the velocity profile varied around the ventricle a single value for the lower limit of normal could not be taken. The regional velocity was standardised to the mean velocity to produce a relative velocity profile, which was displayed for the control group as the median, 25 th, and 75 th centiles (fig 4 ). The standardised velocity profiles of the patients were compared with the control group and any segment with a velocity below the 5 th centile was considered abnormal. These areas were compared with electrocardiographic, perfusion, and angiographic data to assess the correlation of an area of reduced wall motion with the expected site of abnormality.

Figure 4 Regional values of long axis velocity standardised to the mean value at the time of peak long axis wall motion in the control group. Broken lines represent 25 th and 75 th centiles.
Analysis of variance was used to assess differences between groups; post hoc analysis between groups was performed using Scheffé's $F$ test. Statistical significance was defined as $P<0.05$. Correlation between heart rate and wall motion was assessed by Spearman's correlation coefficient. Reproducibility was assessed using the technique described by Bland and Altman. ${ }^{12}$

\section{Results}

A projected three dimensional plane can be used to display the data (fig 5). Figure 6 illustrates the analysis of a normal subject and a patient with a myocardial infarction.
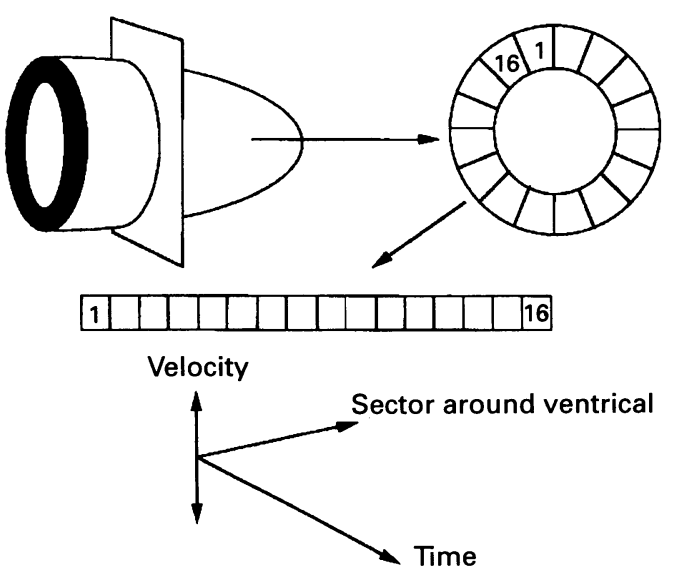

Figure 5 The basal short axis velocity map is divided into 16 sectors and the mean velocity measured. The myocardial ring can then be transformed to a line, left. By using a projected plane of position along one axis and time along the other velocity can be displayed above and below this plane; systole is represented by a trough, diastole by $a$ peak, fig 6.

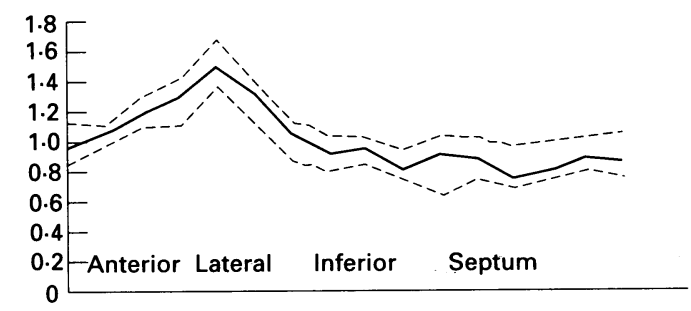




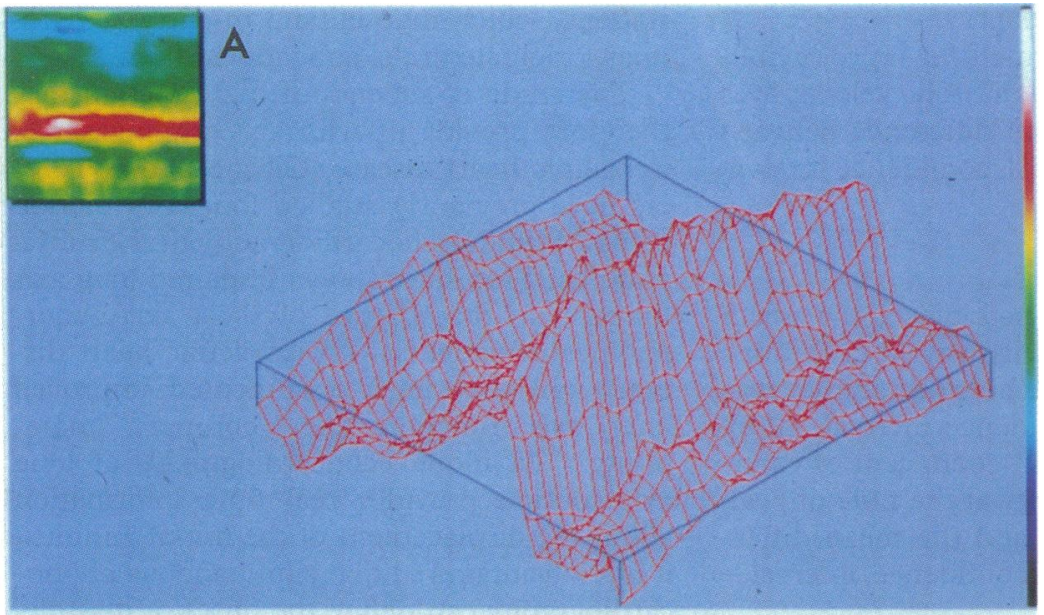

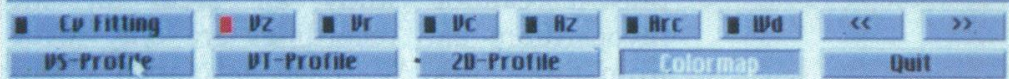

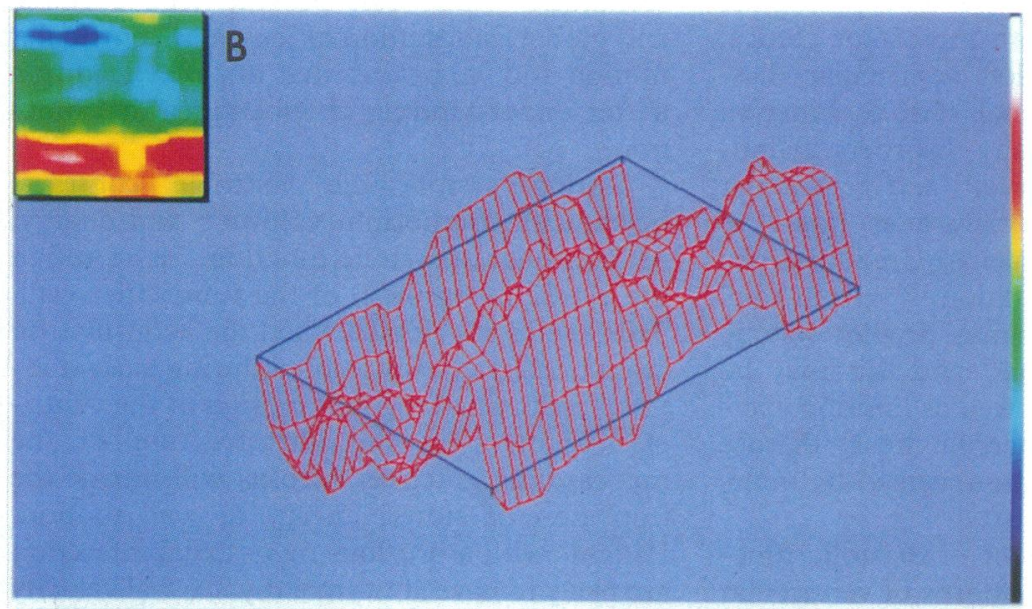

\section{Drrotie}

Figure 6 Left ventricular long axis velocity in a normal subject, top, and a patient with a myocardial infarction, bottom. The colour image represents a bird's eye view with negative velocities in blues and positive velocities in reds and yellows. The normal subject shows an unbroken band during systole and diastole. The patient shows a broken band during systole with reduced and delayed motion during diastole.

Table 1 shows the mean values of maximum, minimum, mean, and range of diastolic velocities during early diastole in each group. The patients with coronary artery disease without infarction had lower group values for maximum and mean peak early diastolic velocity than controls. The coefficient of varia-

Table 1 Mean (SD) measurements of early diastolic long axis velocity for the three groups

\begin{tabular}{llll}
\hline & Controls & $\begin{array}{l}\text { CAD } \\
\text { without infarction }\end{array}$ & $\begin{array}{l}\text { CAD } \\
\text { with infarction }\end{array}$ \\
\hline $\begin{array}{l}\text { Maximum early diastolic } \\
\text { velocity (mm/s) }\end{array}$ & $125(33)$ & $99(30)$ & $80(22)$ \\
& & $<0.05^{\star}$ & $<0.01^{\star}$ \\
$\begin{array}{l}\text { Minimum early diastolic } \\
\text { velocity }(\mathrm{mm} / \mathrm{s})\end{array}$ & $46(21)$ & $27(23)$ & $<0.05 \dagger$ \\
$\begin{array}{l}\text { Mean early diastolic } \\
\text { velocity (mm/s) }\end{array}$ & $82(22)$ & $60.05^{\star}$ & $13(24)$ \\
Coefficient of variation & $27(10)$ & $38(18)$ & $40.01^{\star}$ \\
& & $38(18)$ & $<0.01^{\star}$ \\
& & $52(33)$ & $<0.05^{\star}$ \\
\hline
\end{tabular}

$\mathrm{CAD}=$ Coronary artery disease.

$\star \mathrm{P}$ Value for Scheffé test between control subjects and patients.

$\dagger P$ Value between myocardial infarcts and effort coronary artery

disease without infarction.

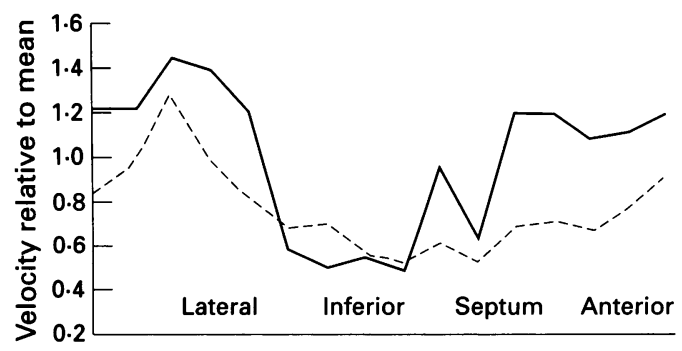

-- Lower 5th centile - Right coronary lesion

Figure 7 Peak early diastolic velocity profile standardised to the mean in a patient with a right coronary artery lesion plotted with the lower 95th centile. The inferior segments in the patient drop below the 95th centile.

tion in the two patient groups showed a greater inhomogeneity of relaxation than controls.

All values were lower in patients with previous infarction than in patients with coronary artery disease without infarction and normal subjects. The coefficient of variation was greater than in controls and patients with coronary artery disease without infarction. At the time of peak early diastolic velocity, four patients had areas of wall motion out of phase with the rest of the ventricle, indicating delayed relaxation in these areas.

There was a marked variation of velocity within each group. Some patients without a history of myocardial infarction had a pattern of wall motion similar to those with a myocardial infarction and others had patterns similar to controls.

There was no correlation between heart rate and mean long axis velocity or its coefficient of variation. Mean heart rate was not statistically different between the three groups (mean (SD) beats/min controls 64 (11), patients with coronary artery disease without infarction 65 (19), patients with infarction 69 (12)).

COMPARISON OF MAGNETIC RESONANCE IMAGING VELOCITY MAPS WITH CLINICAL REGION OF ISCHAEMIA

The myocardium was divided into anterior and inferior territories. In the myocardial infarction group 18 of $26(69 \%)$ patients had one or more areas of velocity below the 5 th centile in areas corresponding to their infarction. In the reversible ischaemia group 13 of $21(62 \%)$ patients had areas of reduced long axis velocity in regions corresponding to the exercise ST segment or reversible thallium perfusion abnormalities (fig 7 , table 2 ).

Table 2 Comparison of clinical site of ischaemic heart disease and presence of wall motion abnormality on magnetic resonance imaging (MRI) velocity mapping

\begin{tabular}{lrll}
\hline & $M R I$ & $\begin{array}{l}\text { MRI } \\
\text { negative }\end{array}$ & $\begin{array}{l}\text { Sensitivity } \\
(\%)\end{array}$ \\
\hline Anterior infarction & 6 & 4 & 60 \\
Inferior infarction & 12 & 4 & 75 \\
Anterior ischaemia & 8 & 3 & 70 \\
Inferior ischaemia & 5 & 5 & 50 \\
\hline
\end{tabular}


SHORT TERM REPRODUCIBILITY

In the 20 studies performed for reproducibility, the mean (SD) early diastolic velocity was 84 (32) $\mathrm{mm} / \mathrm{s}$. The mean difference between studies was $-5 \mathrm{~mm} / \mathrm{s}$ ( $95 \%$ confidence interval -11 to $0 \cdot 76$ ).

\section{INTRAOBSERVER VARIABILITY}

In the 10 studies analysed twice, the mean (SD) early diastolic velocity was $90(29) \mathrm{mm} / \mathrm{s}$ and the mean difference between studies was $0.739 \mathrm{~mm} / \mathrm{s}$ (95\% confidence interval, -0.65 to $2 \cdot 17)$. The mean (SD) coefficient of variation of myocardial velocity at the time of peak velocity was 23.0 (6)\% and the mean difference was $-0.6 \%$ (95\% confidence interval $2 \cdot 2$ to $1 \cdot 0$ ).

\section{Discussion}

Abnormal diastolic function is an early marker of ventricular disease with important clinical implications. Impaired left ventricular diastolic function with normal systolic function has been observed in many disorders including coronary artery disease,,$^{13}$ and ventricular hypertrophy. ${ }^{14}$ In heart failure as many as one third of patients have isolated diastolic abnormalities at presentation. ${ }^{15} 16$ Abnormal diastolic function at rest may predict systolic abnormalities on exertion ${ }^{17}$ and this may be the cause of dyspnoea as well as limiting exercise tolerance. ${ }^{18}$ In ischaemic heart disease these abnormalities can be reversed by interventions such as angioplasty. ${ }^{19} 20$

Much of our assessment of diastolic function has been based on patterns of ventricular filling using techniques such as radionuclide ventriculography and Doppler echocardiography. ${ }^{21}$ Filling patterns are, however, affected by age, heart rate, systolic function, preload, and afterload. ${ }^{22}{ }^{23}$ The relation between flow patterns and diastolic function has been called into question..$^{24}$ Flow across the mitral valve is the result of an atrioventricular pressure gradient which is determined by the left atrial pressure and left ventricular wall motion. ${ }^{25}$ Doppler patterns of ventricular filling do not truly reflect diastolic myocardial function, therefore patterns of wall motion may be a more useful marker of myocardial disease.

The importance of studying subendocardial function is that subendocardial perfusion is affected before that of other layers and to a greater extent in ischaemic heart disease, ${ }^{56}$ and recovery of function takes longer than for other layers. ${ }^{26}$ Subendocardial perfusion is impaired during exercise in left ventricular hypertrophy, even without occlusive coronary disease. ${ }^{27}$ Chronic ischaemia without infarction leads to myocardial fibrosis with the subendocardial layers being affected. ${ }^{28}$ This damage has functional consequences and subendocardial function of the non-ischaemic area needs to be intact for the maintenance of compensatory regional contraction after coronary artery occlusion. ${ }^{29}$ Subendocardial perfusion may be important in the genesis of arrhythmias as premature ventricular depolar- isations, which may initiate re-entry arrhythmias, originate in the subendocardium. ${ }^{30}$

The study of subendocardial function may therefore provide us with an early marker of ischaemic heart disease. Gibson and coworkers have previously studied long axis motion using $M$ mode echocardiography of the mitral annulus. They have shown impaired long axis function in the absence of short axis abnormalities in patients with ischaemic heart disease $^{8}$ and they have documented improved long axis function after coronary angioplasty. ${ }^{31} \mathrm{M}$ mode echocardiography of long axis motion provides real time information about the displacement of the mitral annulus; it has advantages in that simultaneous phonocardiography can define the onset of diastole, but it cannot study all areas of the myocardium and recordings are only made from three sites. We have developed a new technique which can provide true regional and global information of long axis ventricular motion and we believe that this may lead to a better understanding of subendocardial function.

During systole the ventricle contracts beyond its equilibrium volume $\mathrm{e}^{32}$ and energy, proportional to systolic function, ${ }^{33}$ is stored in the elastic component of the ventricular wall. This energy is released when the actin-myosin cross bridges are uncoupled during early diastole, ${ }^{34}$ initiating long axis motion of the ventricle. Changes in the ultrastructure of the myocardium, such as fibrosis, will impair the transition of stored energy to wall motion. Patients with a previous myocardial infarction are likely to have abnormal myocardial velocity because of fibrous tissue at the site of the infarct; these patients were found to have the lowest velocities. They also had the largest variation of regional velocity because of low velocity at the site of the infarction.

Long axis motion in normal subjects results in a negative intraventricular pressure during early diastole..$^{35}$ This decrease in pressure will increase the atrioventricular pressure gradient and augment peak early filling. ${ }^{25} 36$ Impairment in wall motion during early diastole will reduce the decrease in intraventricular pressure and so impair early filling, a commonly used marker of diastolic function. In this study patients with coronary artery disease without infarction also had reduced myocardial velocity and greater inhomogeneity, although not as marked as those with infarction. This will be related to increased subendocardial fibrosis ${ }^{28}$ and the effects of chronic ischaemia. We have shown that the long axis velocity during early diastole is significantly correlated with Doppler parameters of early filling. (Karwatowski SP, Brecker SJD, Yang GZ, Firmin DN, St John Sutton $M$, Underwood SR, unpublished data.) This impairment of early long axis motion may be an important part of the mechanism of altered ventricular filling.

The mean velocities in the patient groups were lower than in the controls, which may reflect a residual effect of drugs. A reduced mean velocity would not affect the assessment 
of regional variation by either coefficient of variation or centile score as these two measures allowed for the mean velocity.

\section{ANATOMICAL SITE OF ISCHAEMIA}

Electrocardiographic criteria are poor in localising the site of ischaemia and so the division of anatomical territories into anterior and inferior is necessarily broad. Magnetic resonance velocity mapping detected regional abnormalities of long axis velocity in $70 \%$ of patients with previous myocardial infarction and in $62 \%$ of patients with reversible ischaemia but no evidence of infarction. A previous echocardiographic study of patients with healed infarctions showed a sensitivity of between 48 and $91 \%$ for the detection of abnormal wall motion depending on the site. ${ }^{37}$ The sensitivity also depends on the size of the infarct. ${ }^{38}$ In patients without infarction echocardiography detected resting abnormalities in 66 of 166 $(40 \%)$ patients with proved coronary artery disease. ${ }^{1}$ Our data suggest that magnetic resonance imaging velocity mapping has a similar sensitivity for the detection of abnormal wall motion in patients with healed myocardial infarction and better sensitivity for detecting abnormalities in patients with reversible ischaemia.

\section{LIMITATIONS}

Like all cross sectional imaging techniques, the method used measures myocardial velocity in a single plane and therefore does not image a constant part of the myocardium throughout the cycle. Long axis velocities depend, however, on the function of all of the myocardium between the imaging plane and the apex, and this is a strength of the technique because localised regional abnormalities are likely to be detected even if not within the imaging plane. Echocardiographic and radionuclide methods of assessing diastolic left ventricular function are more widely available than magnetic resonance with velocity mapping and we have not compared our findings with more commonly used measures of radial motion. Whether the flexibility and sensitivity of our technique will prove an advantage in clinical practice is the subject of further studies. It may be appropriate to delay formal comparison with other imaging techniques until a number of technical advances have been implemented. These include saturation of the blood pool signal to avoid artefact over the myocardium in the velocity maps, and real-time acquisition which will remove artefact from the averaging of nonidentical cycles.

1 Lewis SJ, Sawada SG, Ryan T, Segar DS, Armstrong WF, Feigenbaum $H$. Segmental wall motion abnormalities in the absence of clinically documented myocardial infarction: clinical significance and evidence of hibernating myocardium. Am Heart f 1991;121:1088-94.

2 Kuesherer HF, Ruffman K, Schaefer E, Kuebler W. Doppler echocardiographic assessment of left ventricula filling dynamics in patients with coronary heart disease and normal systolic function. Eur Heart $f$ 1988;9.
649-56.

3 Pozzoli MMA, Fioretti PM, Salustri A, Reijs AEM, Roelandt JRTC. Exercise echocardiography and technetium-99m MIBI single photon emission computed tomography in the detection of coronary artery disease. Am $\mathcal{F}$ Cardiol 1991;67:350-5.

4 Miyazaki S, Guth BD, Miura T, Indolfi C, Schulz R, Ross $\mathrm{JJ}$. Changes in left ventricular diastolic function in exercising dogs without and with ischaemia. Circulation 1990;81:1058-70.

5 Momomura S, Ferguson JJ, Miller MJ, Parker JA, Grossman W. Regional myocardial blood flow and left ventricular diastolic properties in pacing-induced ischaemia. $f \mathrm{Am}$ Coll Cardiol 1991;17:781-9.

6 Torry RJ, Myers JH, Adler AL, Liut CL, Gallagher KP. Effects of non transmural ischaemia on inner and outer wall thickening in the canine left ventricle. Am Heart $f$ wall thickening in

7 Greenbaum R, Ho SY, Gibson D, Becker A, Anderson R. Left ventricular fibre architecture in man. Br Heart $f$ 1981;45:248-63.

8 Jones CJH, Raposo L, Gibson DG. Functional importance of the long axis dynamics of the human left ventricle. $\mathrm{Br}$ Heart f 1990;63:215-20.

9 Henein MY, Brecker SJD, Xiao HB, Gibson DG. Resting left ventricular diastolic abnormalities in coronary artery stenosis and myocardial infarction [abstract]. XIV Congress of the European Society of Cardiology; 1992; Barcelona. Eur Heart $\mathcal{f}$ 1992;13(abstr suppl):23.

10 Karwatowski SP, Mohiaddin R, Yang GZ, et al. Noninvasive assessment of regional left ventricular long ris motion using ment of regional left ventricular long in normal subjects. $\mathcal{F}$ Magn Reson Imaging 1994;4:151-5.

11 Nayler GL, Firmin DN, Longmore DB. Blood flow imaging by cine magnetic resonance. $\mathcal{F}$ Comput Assist Tomogr 1986;10:715-22.

12 Bland JM, Altman DG. Statistical methods for assessing agreement between two methods of clinical measurement. Lancet 1986;i:307-10.

13 Polack JF, Kemper AJ, Bianco JA, Parisi AF, Tow DE. Resting early peak diastolic filling rate: a sensitive index of myocardial dysfunction in patients with coronary artery myocardial dysfunction in patients
disease. $₹ \mathrm{Nucl}$ Med $1982 ; 23: 471-8$.

14 Fujji J, Watanabe H, Koyama S, Kato K. Echocardiographic study on diastolic posterior wall movement and left ventricular filling by disease category. $\mathrm{Am}$ Heart f 1979;98:144-52.

15 Soufer R, Wohlgelernter D, Nestor A, et al. Intact systolic left ventricular function in clinical congestive heart failure. Am $\mathcal{A}$ Cardiol 1985;55:1032-6.

16 Ghali JK, Kadakia S, Cooper RS, Liao YL. Bedside diagnosis of preserved versus impaired left ventricular systolic function in heart failure. Am $\mathcal{F}$ Cardiol 1991;67: 1002-6.

17 Perrone FP, Bacharach SL, Dilsizian V, Bonow RO. Impaired left ventricular filling and regional diastolic asynchrony at rest in coronary artery disease and relation to exercise-induced myocardial ischaemia. Am $₹ \mathrm{Cardiol}$ 1991;67:356-60.

18 Davies S, Fussell A, Jordan S, Poole-Wilson P, Lipkin D. Abnormal diastolic filling patterns in chronic heart failure-relationship to exercise capacity. Eur Heart $\mathcal{f}$ ure-relationship

19 Snow FR, Gorcsan J, Lewis SA, Cowley MJ, Vertrovec GW, Nixon JV. Doppler echocardiographic evaluation of left ventricular diastolic function after percutaneous transluminal coronary angioplasty for unstable angina pectoris or acute myocardial infarction. $\mathrm{Am} \mathcal{F}$ Cardiol 1990;65:840-4.

20 Nienaber CA, Brunken RC, Sherman CT, et al. Metabolic and functional recovery of ischaemic human myocardium after coronary angioplasty. $\mathcal{F}$ Am Coll Cardiol 1991;18:966-78.

21 Nishimura R, Abel M, Hatle L, Tajik A. Assessment of diastolic function of the heart: background and current applications of Doppler echocardiography. Part II clinical studies. Mayo Clin Proc 1989;64:181-204.

22 Benjamin E, Levy D, Anderson K, et al. Determinants of Doppler indexes of left ventricular diastolic function in normal subjects (the Framingham Heart Study). $A m \mathcal{F}$ Cardiol 1992;70:508-15.

23 Himura Y, Kumada T, Kambayashi M, Hayashida W, Ishikawa N, Nakamura Y. Importance of left ventricular Ishikawa N, Nakamura Y. Importance of left ventricular systolic function in the assessment of left ventricular
diastolic function with Doppler trans-mitral flow velocity diastolic function with Doppler trans-mitral flow

24 recording. F Am Coll Cardiol 1991;18:753-60. Preload dependence of Doppler derived indices of left ventricular diastolic function in humans. $₹ \mathrm{Am}$ Coll ventricular diastolic funct

25 Takagi $S$, Yokota $M$, Iwase $M$, et al. The important role of left ventricular relaxation and left atrial pressure in the left ventricular filling profile. Am Heart $\mathcal{F} 1989 ; 118$ : 954-62.

26 Bolli R, Patel B, Hartley C, Thornby J, Jeroudi M, Roberts $R$. Nonuniform transmural recovery of contractile function in stunned myocardium. Am $\mathcal{f}$ Physiol 1989; 257:H375-85.

27 Bache RJ, Vrobel TR, Ring WS. Regional myocardial blood flow during exercise in dogs with chronic left ventricular hypertrophy. Circ Res 1981;48:473-81.

28 Hess OM, Schneider J, Nonogi H, et al. Myocardial structure in patients with exercise-induced ischaemia. Circulation 1988;77:967-77. 
29 Birkland S, Westby J, Hexenberg K, Grong K, Lekven J. Compensatory regional contraction following coronary artery occlusion depends on subendocardial hyperaemia and hyperkinesis. Eur Heart 7 1992;13:1207-16.

30 Janse MJ, Kleber AG, Capucci A, Coronel R, WilmsSchopman F. Electrophysiological basis for arrhythmias caused by acute ischaemia. $\mathcal{F} \mathrm{Mol}$ Cell Cardiol 1986; 18:339-55.

31 Henein M, Preistly K, Davarashvili T, Buller N, Gibson $D$. Early changes in left ventricular subendocardial function after successful coronary angioplasty. $\mathrm{Br}$ Heart $\mathcal{f}$ 1993;69:501-6.

32 Brecher GA. Critical review of recent work on ventricular diastolic suction. Circ Res 1958;6:554-6.

33 Caillet D, Crozatier B. Role of myocardial restoring forces in the determination of early diastolic peak velocity of fibre lengthening in the conscious dog. Cardiovasc Res 1982;16:107-12.

34 Pouleur H. Diastolic dysfunction and myocardial energetics.
Eur Heart f 1990;11(suppl C):30-4

35 Suga H, Goto Y, Igarashi Y, Yamada O, Nozawa $T$, Yasumura Y. Ventricular suction under zero source pressure for filling. Am $\mathcal{F}$ Physiol 1986;251:H47-55.

36 Udelson JE, Bacharach SL, Cannon RO, Bonow RO Minimum left ventricular pressure during $\beta$-adrenegic stimulation in normal subjects. Circulation 1990;82: 1174-82.

37 Freeman A, Giles R, Walsh W, Fischer R, Murray I, Wilcken $D$. Regional left ventricular wall motion assessment: comparison of two-dimensional echocardiography and radionuclide angiography with contrast angiography in healed myocardial infarction. Am $\mathcal{f}$ Cardiol 1985;56: 8-12.

38 Pandian N, Skorton D, Collins S, et al. Myocardial infarct threshold for two-dimensional echocardiographic detection: sensitivity of systolic wall thickening and endocardial motion abnormalities in small versus large infarcts. Am $\mathcal{F}$ Cardiol 1985;55:551-5. 